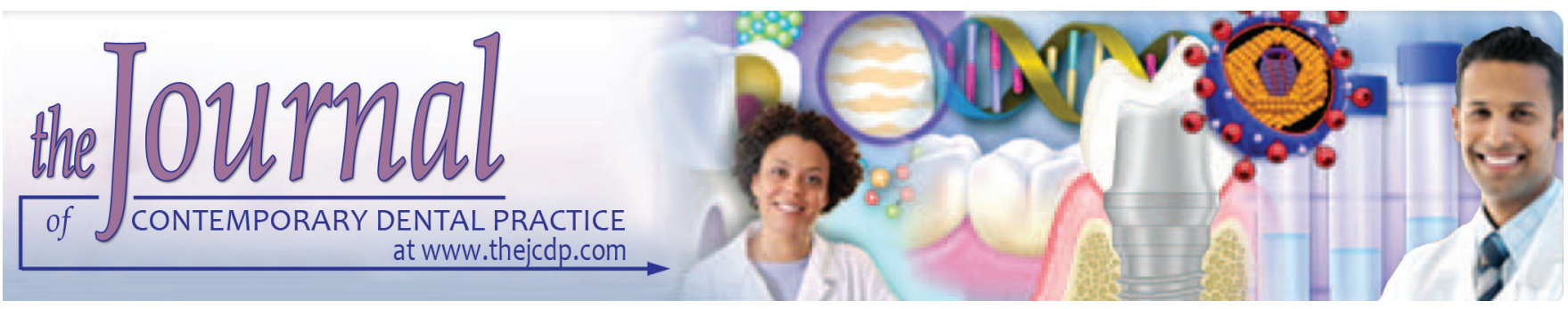

\title{
Layered Base Plate Blocks and Operative Dentistry Skills
}

\author{
${ }^{1}$ Mai E Khalaf, ${ }^{2}$ Qoot Alkhubaizi, ${ }^{3}$ Qasem D Alomari
}

\begin{abstract}
Aim: Preclinical dental training is essential for the development of psychomotor skills necessary for clinical practice. The study aimed to investigate the impact of teaching with a layered base plate blocks on cavity preparations and students' self-perceived confidence, readiness, and ability.
\end{abstract}

Materials and methods: A cross-sectional study recruited 52 dental students into two groups; one trained (test) with layered base plate and the other without (control). Students answered an eight-question survey to assess self-perceived confidence, readiness, and ability for performing cavity preparation at the start of their first preclinical operative dentistry course. Students prepared one molar tooth for a class I cavity and two for class II cavities. Preparations were assessed for different elements of depth and outline extension by two blinded examiners.

Results: Statistically significant differences were found between the median scores with respect to the preparation of class II cavities among students exposed to layered base plate (MannWhitney U-test, $p<0.05)$. There were no significant differences between the median scores awarded with respect to the preparation of class I cavity. A statistically significant difference was reported in self-perceived confidence among students who trained with the layered base plate $\left(\chi^{2}, p<0.05\right)$.

Conclusion: Training on the layered base plate blocks increased students' initial confidence level in performing cavity preparations, and improved the preparation skills in class II cavity.

Clinical significance: This study explores the methods of enhancing motor skills taught in preclinical operative dentistry courses, especially in short academic programs.

Keywords: Cavity outline, Layered base plate blocks, Operative dentistry.

How to cite this article: Khalaf ME, Alkhubaizi Q, Alomari QD. Layered Base Plate Blocks and Operative Dentistry Skills. J Contemp Dent Pract 2018;19(5):554-559.

Source of support: Nil

Conflict of interest: None

${ }^{1-3}$ Department of General Dental Practice, Faculty of Dentistry Kuwait University, Safat, Kuwait

Corresponding Author: Qoot Alkhubaizi, Department of General Dental Practice, Faculty of Dentistry, Kuwait University P.O. Box 24923, Safat, 13110, Kuwait, e-mail: qalkhubaizi@ hsc.edu.kw

\section{INTRODUCTION}

Dental education is a complex combination of didactic and practical training. While enrolled in lengthy dental programs, undergraduates are expected to attain a unique and diverse collection of competencies. ${ }^{1}$ Dental competence requires good perceptual and visual skills, not only for gathering information but also for judging positions, distances, and the sizes of objects and shapes. ${ }^{2}$ Preclinical laboratory instruction in the field of operative dentistry integrates exercises and tasks

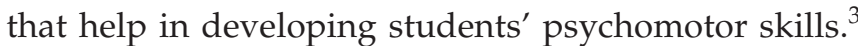
Traditionally, psychomotor skills are developed through a combination of two-dimensional drawing projects and exercises to carve teeth from oversized blocks. ${ }^{3}$ With recent advancing technologies, dental education has embraced the use of computerized dental simulation systems with computer-assisted learning increasing in significance. ${ }^{4}$ However, even with the supplementation of didactic teaching with learner-centered approach to dental education, the speed of this change in learning style continues to vary between institutions as well as between individual academics and countries. ${ }^{5}$ Despite the availability of computerized learning technologies, these systems remain at their infancy and are in constant overhaul. These systems have yet to replace all traditional teaching aids in dental schools worldwide and computeraided learning continues to be in use as an adjunct to conventional teaching. ${ }^{6}$

A number of studies in the 1980s and 1990s demonstrated the importance of orienting learners prior to task performance, providing frequent "formative" feedback to students, guiding learners with questions and helping students to understand the desired outcome of a technical procedure. ${ }^{7-11}$ More recently, a number of learning strategies have been identified that are strongly associated with modifying clinical behaviors. These include persistent feedback on performance, observed performance, peer feedback, and participation in simulations that allow personal reflection on performance. ${ }^{12}$ 
Dental students enter the preclinical stage of their operative dental training with a range of initial levels of psychomotor skills and rates of learning. ${ }^{13}$ Students may have difficulty perceiving basic horizontal and vertical dimensions that must be combined into a threedimensional model. ${ }^{14} \mathrm{~A}$ variety of lead-up activities have been developed to assist in early development of psychomotor skills for operative dentistry. ${ }^{15}$ Of these activities, the \#9683 Learn-A-Prep II (LAP II) (Whip mix) layered base plate blocks are available to be used in the initial instructional levels for students. These blocks utilize color and/ or material hardness to mimic enamel, dentin, and pulp tissue. ${ }^{13}$ The overall goal of the design of these blocks is to foster an understanding of movement through vertical and horizontal space by the ability to create precise threedimensional preparations. ${ }^{13}$ These teaching blocks have been and are currently used in preclinical operative dentistry courses to help students gain familiarity with handpiece operation prior to attempting various preparation techniques on plastic dentoform teeth. ${ }^{7}$ Teaching blocks have also been utilized as predictive models of students' skills. Assessment and evaluation of student performance on teaching blocks are used to identify the need for early intervention and individualize student instruction which may lead to better overall preclinical course performance and a higher level of preclinical competence. ${ }^{13}$

Studies have been conducted that assess whether early student performance with a dental hand-piece on a LAP II was predictive of performance on subsequent preclinical examinations in preclinical operative dentistry courses. However, there are no reported studies to compare the performance on preclinical operative dentistry exercises between cohorts taught with and without LAP II.

This study aimed (a) to investigate the impact of using LAP II block as a teaching tool on self-perceived confidence, readiness, and ability in preclinical operative dentistry exercises at the beginning and end of a preclinical operative dentistry course; (b) to investigate the effect of the introduction of the LAP II on the overall students' performance in cavity preparation skills of preclinical operative dentistry at the beginning, middle, and end of their preclinical operative dentistry course.

\section{MATERIALS AND METHODS}

The study was approved by the Joint Committee for the Protection of Human Subjects in Research of the Health Science Center, Kuwait University and Kuwait Institute for Medical Specialization. All participants signed a consent form prior to completing the study. The study population was drawn from two consecutive years of dental students at Kuwait University. The first group (control) included 26 students who had no exposure to the LAP II during their orientation module to basic dental sciences. The second group was the test group (test, $n=26$ ), who were given LAP II exercises during their orientation module. When students started their Pre-clinical Operative Dentistry course, they completed an eight-item Likert scale survey (self-perception) to assess their selfperceived confidence, readiness, and ability to perform certain elements of cavity preparation. The survey was developed by one of the authors of this article (MK). This didactic and practical course runs over 15 weeks, and consists of basic principles of operative dentistry and dental materials. As part of the course, students prepared one first molar tooth for a class I cavity and two first molar teeth for class II cavity preparations at the beginning, middle, and end of the semester and handed them for assessment to the researcher. These cavities served as a method to evaluate the students' prior exposure to the LAP II (Flow Chart 1).

Guidelines for tooth preparation were expected to follow those taught in the course. Students were instructed to cut a cavity preparation for an amalgam restoration. The cavities, class I and II were assessed for depth, mesiodistal, buccolingual width, and proximal box outline by two blinded examiners who were not involved in teaching the course (coauthor QA and volunteer AM). The depth and width of the cavities were measured using a World Health Organization periodontal probe, and the measurements were handled as categorical variables (Table 1 for assessment criteria).

\section{Statistical Analysis}

Data were analyzed by SPSS Statistics for Windows, version 17.0 (SPSS Inc., Chicago, Illinois, USA). MannWhitney U-tests were used to compare the median scores awarded by the two examiners for the cavity preparations for control and test groups. A Pearson's chi-square test was used to compare the difference in item responses for control and test groups at entry of the operative dentistry course. Statistical significance level was set at $\mathrm{p}<0.05$.

Flow Chart 1: Consort diagram for the course of the study

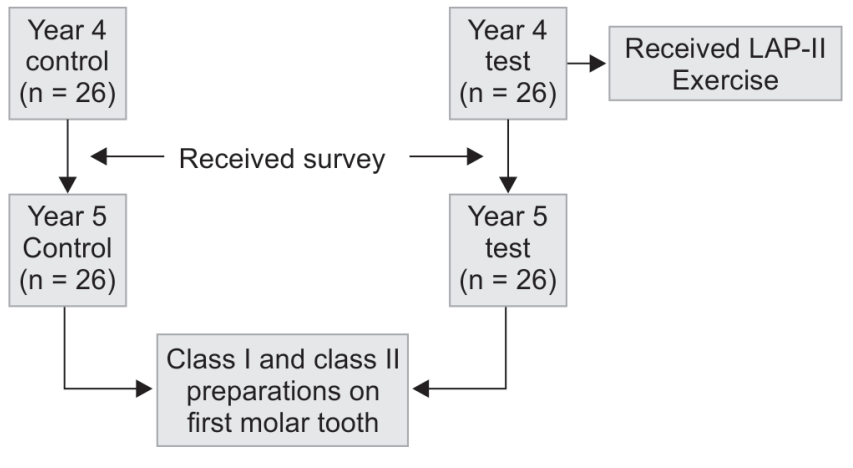


Table 1: Assessment criteria used by the examiners for class I and II cavity preparation

\begin{tabular}{lll}
\hline Cavity classification & Score & Examiner's assessment parameters \\
\hline Class I & Depth & $<1.5 \mathrm{~mm}$ \\
& 1 Shallow & $2-3 \mathrm{~mm}$ \\
& 2 Ideal & $>3 \mathrm{~mm}$ \\
& 3 Deep & \\
& Mesiodistal outline & Did not include all fissures \\
& 1 Underprepared & All fissures included but no marginal ridges or cusps \\
& 2 Ideal & $<2 \mathrm{~mm}$ remains of marginal ridges or cusps \\
& 3 Overprepared & \\
& Buccolingual outline & $<1 \mathrm{~mm}$ \\
& 1 Underprepared & $1-2 \mathrm{~mm}$ \\
& 2 Ideal & $>3 \mathrm{~mm}$ \\
& Proximal box & \\
1 Underprepared & Proximal contact not open \\
2 Ideal & Contact open without extension into facial/lingual surfaces \\
& 3 Overprepared & Contact open with extension into lingual and/or buccal surfaces \\
\hline
\end{tabular}

Table 2: Median scores for examiners' assessment of class I and II cavity preparations on a first molar tooth

\begin{tabular}{|c|c|c|c|c|c|c|}
\hline Course timing & Cavity design & Outline & Control & Test & $\begin{array}{l}\text { Mann-Whitney } \\
\text { U-test }\end{array}$ & $p$-value \\
\hline \multirow{3}{*}{ Start } & \multirow{3}{*}{ Class I } & Depth & 1.45 & 1.48 & $1,320.5$ & 0.815 \\
\hline & & Mesiodistal & 1.95 & 1.80 & $1,216.0$ & 0.333 \\
\hline & & Buccolingual & 2.03 & 2.15 & $1,260.5$ & 0.526 \\
\hline \multirow[t]{4}{*}{ Middle } & \multirow[t]{4}{*}{ Class II } & Depth & 1.19 & 1.35 & $1,139.0$ & 0.072 \\
\hline & & Mesiodistal & 1.88 & 2.17 & $1,088.0$ & 0.083 \\
\hline & & Buccolingual & 1.60 & 2.07 & 923.0 & $0.004^{*}$ \\
\hline & & Proximal box & 2.31 & 1.86 & $1,042.5$ & $0.047^{*}$ \\
\hline \multirow[t]{4}{*}{ End } & \multirow[t]{4}{*}{ Class II } & Depth & 1.20 & 1.49 & 921.0 & $0.006^{*}$ \\
\hline & & Mesiodistal & 1.76 & 2.31 & 925.5 & $0.012^{*}$ \\
\hline & & Buccolingual & 1.34 & 1.79 & 790.5 & $<0.001^{*}$ \\
\hline & & Proximal box & 1.48 & 1.94 & 913.0 & $0.008^{*}$ \\
\hline
\end{tabular}

*Significant difference between median scores for Control-2012 are the students with no prior exposure to LAP-II block (see consort diagram) and Test-2013 are those who received the LAP-II block training at $p<0.05$

\section{RESULTS}

\section{Cavity Preparation Exercise}

The results of Mann-Whitney U-tests comparing the median scores awarded by the two examiners for the cavity preparation exercise for control and test groups are presented in Table 2. There were no significant differences between the median scores awarded for the two groups with respect to the preparation of the class I cavities (U statistic, $\mathrm{p}>0.05$ ). In contrast, statistically significant differences were found between the median scores for control and test groups with respect to the buccolingual outline, proximal box of the tooth prepared mid-course, and all elements of class II completed at the end of the course cavity preparation (U statistic, $\mathrm{p}>0.05$ ) (Table 2 ). Therefore, results indicate an overall improvement in the performance of the test group compared with the control group in the preparation of the occlusal portions of class II preparations. In both class II preparations, the improvement was seen in the depth preparation of the occlusal portion in addition to the buccolingual outline, wherein both cases students in the test group showed more ideal tooth preparations.

\section{Self-perception Survey}

A Pearson's chi-square test was carried out to explore the differences in the survey answers among both batches at the onset of the operative dentistry course. Answers to the survey were grouped to create three categorical variables as follows: Strongly agree, undecided, and strongly disagree with disagree. The test revealed a statistically significant difference between answers to most items of the survey at the entry of the operative dentistry course among the control group participants compared with the test group. Specifically, items 6 and 7 indicate that training using the layered base plate enhanced self-perceived confidence, readiness, and ability at cutting cavity preparations (Table 3). 
Layered Base Plate Blocks and Operative Dentistry Skills

Table 3: Pearson's chi-square test for differences of self-perceived confidence, readiness, and ability in cutting a class I and II cavities between control and test batches at entry of the operative dentistry course

\begin{tabular}{|c|c|c|c|c|c|}
\hline \multirow[b]{2}{*}{ Item } & & \multirow[b]{2}{*}{ Responses } & \multicolumn{2}{|c|}{ Entry of course } & \multirow[b]{2}{*}{$p$-value } \\
\hline & & & Control & Test & \\
\hline \multirow[t]{3}{*}{1} & I feel confident in controlling a high speed hand piece & Agree & 8 & 11 & 0.250 \\
\hline & & Undecided & 10 & 11 & \\
\hline & & Disagree & 8 & 3 & \\
\hline \multirow[t]{3}{*}{2} & I am able to prepare the external outline of a tooth for a & Agree & 0 & 8 & $0.000^{*}$ \\
\hline & class I cavity & Undecided & 12 & 15 & \\
\hline & & Disagree & 14 & 1 & \\
\hline \multirow[t]{3}{*}{3} & I am able to prepare $1 \mathrm{~mm}$ into dentin (preparation depth) & Agree & 2 & 0 & $0.000^{*}$ \\
\hline & for a class I cavity & Undecided & 11 & 10 & \\
\hline & & Disagree & 13 & 14 & \\
\hline \multirow[t]{3}{*}{4} & I am able to prepare the external outline of a tooth for a & Agree & 0 & 9 & $0.000^{*}$ \\
\hline & class II cavity & Undecided & 10 & 12 & \\
\hline & & Disagree & 16 & 4 & \\
\hline \multirow[t]{3}{*}{5} & I am able to prepare $1 \mathrm{~mm}$ into dentin (preparation depth) & Agree & 0 & 8 & $0.000^{*}$ \\
\hline & for a class II cavity & Undecided & 12 & 15 & \\
\hline & & Disagree & 14 & 2 & \\
\hline \multirow[t]{3}{*}{6} & I am ready to prepare a clinically acceptable class I cavity & Agree & 0 & 16 & $0.000^{*}$ \\
\hline & independently & Undecided & 9 & 7 & \\
\hline & & Disagree & 17 & 2 & \\
\hline \multirow[t]{3}{*}{7} & I am ready to prepare a clinically acceptable class II cavity & Agree & 0 & 7 & $0.000^{*}$ \\
\hline & independently & Undecided & 9 & 15 & \\
\hline & & Disagree & 17 & 3 & \\
\hline \multirow[t]{3}{*}{8} & I had sufficient time to prepare for the first practical & Agree & 1 & 9 & $0.000^{*}$ \\
\hline & examination & Undecided & 16 & 7 & \\
\hline & & Disagree & 9 & 9 & \\
\hline
\end{tabular}

*Significant difference between item answers for control-2012 and test-2013 at $p<0.05$

\section{DISCUSSION}

Students receiving training on the LAP II blocks before the start of the preclinical operative dentistry course were found to have improved in their preparation of the outline forms of class II cavities. Prior practice on the LAP II had an effect on students' perceived confidence, readiness, and ability upon entering the operative dentistry course.

Findings showed a significant improvement amongst the group of students trained with the LAP II at a later time during the operative dentistry course. It has been reported previously that there was a correlation found between initial student ability to prepare patterns on an acrylic block with subsequent practical performance, and no reports on which aspect of the pattern preparation was most predictive. ${ }^{16}$ More recently, analysis has revealed that the depth aspect of performance on the LAP II was predictive of practical performance early in operative dentistry courses. ${ }^{13}$ However, this finding was also challenged, as it was reported that in the study, data presented showed that only one relationship (acceptable depth) out of eight tested was associated with performance on one early laboratory practical. ${ }^{13}$

This study also investigated the ability to estimate depth and distance, which are central key elements in the teaching of preclinical operative dentistry. The ability to estimate depth and distance, whether and how it can be taught, or whether there is an association among ability, stereopsis, and dental performance continues to be reported as one that has not been thoroughly examined. ${ }^{2}$ We found that there is a significant improvement in depth preparation of students in correlation with the use of the LAP II, which is promising. This is due to the fact that it has been reported that many students, particularly in the early years of dental education, have difficulty to accurately gauge small depths and distances. ${ }^{2}$ It was suggested that students who show an initial inability to conceptualize depths and distances would have difficulty preparing teeth to specific measurements, and this in turn could impact their preclinical and clinical performance. ${ }^{2}$ Findings of this study showed that students exposed to LAP II were able to improve their depth preparation at a later stage in the course, indicating that there is a benefit to using a layered base plate in teaching.

The study also took into account students' selfperception of their confidence, readiness, and ability in performing operative procedures. It was found that students who received training on the LAP II were more confident of their ability to perform certain elements of cavity preparation at the start of the operative dentistry course. There is a consensus that students' perspective 
should be taken into consideration in all discussions and decisions regarding dental education. Moreover, students should be encouraged to take responsibility for their own learning by providing different educational tools that employ a variety of methods in order to address different learning styles. ${ }^{1}$ The use of LAP II provides a relatively low-cost educational tool that would allow students to practice with or without instructor presence different elements of hand-piece manipulation and depth preparation. However, even with the presence of that freedom for practice and use, findings here were not reflective of students' confidence.

The study found applicability to the use of LAP II as a supplementary teaching tool for the introduction of students to the basic principles of operative dentistry. It continues to be reported that for novice students, explicit directions given in small steps and provision of timely feedback on performance are techniques that facilitate the learning of motor skills. ${ }^{17}$ Recognition skills in which the students learn to visualize an appropriate end result should be formally taught and emphasized prior to any skill performance. Teaching novice students how to accurately self-assess may improve performance or, at a minimum, associate performance with self-assessment capabilities ${ }^{17}$ In this case, the use of the LAP II blocks for a brief time may have had only a small significant effect on one element of multiple elements in cavity preparation but nonetheless, it did make a contribution to a multifactorial learning experience. The use of these blocks can still continue to be employed along with more recent technology. As reports continue to investigate the use of virtual reality, simulation systems in teaching and evaluating manual dexterity continue to appear to produce valid and reliable results. ${ }^{18-21}$ Studies comparing visual recognition skills acquired by traditional and computer-based curricula in dental morphology have found that the latter can be a valuable tool to prepare students for the next learning objective and acquisition of motor skills. ${ }^{22,23}$ Preclinical operative dental education can continue to improve its teaching outcomes by the utilization of more traditional teaching aids while gradually incorporating newer technology that will inevitably predominate dental education.

One of the strengths of this study is that it is the first one conducted at our faculty where dental students receive some of the shortest programs in preclinical and clinical dental training. Therefore, this study addresses the urgent need to explore methods to enhance and support teaching of students who require intense exposure to manual skills at a short time. Despite using three preparations to make our overall assessment of clinical performance, those preparations were carried out at different time points of the operative dentistry course and therefore, reflected a trajectory of improvement in manual dexterity.
Our sample size, though small, is reflective of the student intake size at Kuwait University. It was not possible to include further intakes of students due to changes in curricular structure from discipline-based courses to modular at Kuwait. However, a sample size of 26 in each group provided sufficient power to conduct Mann-Whitney U-test. If the sample size was too small, then it would not have been possible to get any significant results.

\section{CONCLUSION}

Practice on the LAP II blocks did not impact the initial cavity preparations performed by students. Class II preparation skills were significantly improved later in the teaching semester. The use of LAP II blocks improved student's self-perceived confidence in performing cavity preparations.

\section{CLINICAL SIGNIFICANCE}

This study explored the impact of using a layered base plate block on the cavity preparation skills and selfperceived confidence of students in preclinical operative dentistry course. Results revealed that using the base plate enhanced motor skills taught in preclinical operative dentistry courses, especially those displayed later on in the course rather than initially at the start of the course.

\section{ACKNOWLEDGMENTS}

The authors sincerely appreciate the assistance of Prof Hien Ngo and Dr Alexander Moule (AM) who assisted in the project. The authors of this manuscript certify that they have no proprietary, financial, or other personal interest of any nature or kind in any product, service/ company that is presented in this article.

The study was approved by the Joint Committee for the Protection of Human Subjects in Research of the Health Science Center, Kuwait University and Kuwait Institute for Medical Specialization. All participants signed a consent form prior to completing the study.

All authors contributed to the conception, design, data collection, analysis, and preparation of the manuscript. All authors read and approved the manuscript.

\section{REFERENCES}

1. Divaris K, Barlow PJ, Chendea SA, Cheong WS, Dounis A, Dragan IF, Hamlin J, Hosseinzadeh L, Kuin D, MitrirattanakulS, et al. The academic environment: the students' perspective. Eur J Dent Educ 2008 Feb;12(Suppl 1):120-130.

2. Dimitrijevic T, Kahler B, Evans G, Collins M, Moule A. Depth and distance perception of dentists and dental students. Oper Dent 2011 Sep-Oct;36(5):467-477.

3. ObrezA, Briggs C, Buckman J, Goldstein L, LambC, KnightWG. Teaching clinically relevant dental anatomy in the dental 
curriculum: description and assessment of an innovative module. J Dent Educ 2011 Jun;75(6):797-804.

4. SchittekM,Mattheos N,Lyon HC,Attstrom R.Computer assisted learning. A review. Eur J Dent Educ 2001 Aug;5(3):93-100.

5. Nattestad A, Attstrom R, Mattheos N, Ramseier C, Canegallo L, Eaton K, Feeney L, Goffin G, Markovska N, Maixner W, et al. 4.1 web-based interactive learning programmes. Eur J Dent Educ 2002;6 (Suppl 3):127-137.

6. Rosenberg H, Grad HA, Matear DW. The effectiveness of computer-aided, self-instructional programs in dental education: a systematic review of the literature. J Dent Educ 2003 May;67(5):524-532.

7. Feil PH, Guenzel PJ, Knight GW, Geistfeld R. Designing preclinical instruction for psychomotor skills (I) - theoretical foundations of motor skill performance and their applications to dental education. J Dent Educ 1994 Nov-Dec; 58(11-12):806-812.

8. Feil PH, Reed T, Hart JK. Continuous knowledge of results and psychomotor skill acquisition. J Dent Educ 1986 Jun;50(6):300-303.

9. Feil $\mathrm{P}$, Reed T, Hart JK. The transfer effect of leadup activities. J Dent Educ 1990 Oct;54(10):609-611.

10. Knight GW, Guenzel PJ, Feil P. Using questions to facilitate motor skill acquisition. J Dent Educ 1997 Jan;61(1):56-65.

11. Feil PH, Reed T. The effect of knowledge of the desired outcome on dental motor performance. J Dent Educ 1988 Apr;52(4):198-201.

12. Henzi D, Davis E, Jasinevicius R, Hendricson W. North american dental students' perspectives about their clinical education. J Dent Educ 2006 Apr;70(4):361-377.

13. Boushell LW, Walter R, Phillips C. Learn-a-prep II as a predictor of psychomotor performance in a restorative dentistry course. J Dent Educ 2011 Oct;75(10):1362-1369.
14. Udin RD, Bamrud JD, Johnson R, Yaari A. The effectiveness of a layered baseplate training aid in the preclinical instruction of second-year dental students. Quintessence Int 1991 Aug;22(8):659-664.

15. Feil PH. A theory of motor performance and its applications to preclinical dental skill acquisition. J Dent Educ 1989 Apr;53(4):226-232.

16. Wong AY, Watson JF, Thye RP. Evaluation of predictor variables for a self-instructional preclinical course. J Dent Educ 1979 Nov;43(12):637-640.

17. Hauser AM, Bowen DM. Primer on preclinical instruction and evaluation. J Dent Educ 2009 Mar;73(3):390-398.

18. Gal GB, Weiss EI, Gafni N, Ziv A. Preliminary assessment of faculty and student perception of a haptic virtual reality simulator for training dental manual dexterity. J Dent Educ 2011 Apr;75(4):496-504.

19. Buchanan JA. Experience with virtual reality-based technology in teaching restorative dental procedures. J Dent Educ 2004 Dec;68(12):1258-1265.

20. Wierinck E, Puttemans V, Swinnen S, van Steenberghe D. Effect of augmented visual feedback from a virtual reality simulation system on manual dexterity training. Eur J Dent Educ 2005 Feb;9(1):10-16.

21. Urbankova A. Impact of computerized dental simulation training on preclinical operative dentistry examination scores. J Dent Educ 2010 Apr;74(4):402-409.

22. Bogacki RE, Best A, Abbey LM. Equivalence study of a dental anatomy computer-assisted learning program. J Dent Educ 2004 Aug;68(8):867-871.

23. Wallen ES, Schulein TM, Johnson LA. A computer program to aid in visual concept development in dentistry. Comput Methods Programs Biomed 1997;52(2):105-115. 